\title{
A Japanese Family Suffering from Familial Juvenile Hyperuricemic Nephropathy due to a Rare Mutation of the Uromodulin Gene
}

\author{
Mayuka Nakayama ${ }^{a}$ Yasukiyo Mori ${ }^{\text {a }}$ Noriyoshi Ota $^{a}$ \\ Mami Ishida $^{a}$ Yayoi Shiotsu $^{a}$ Eiko Matsuoka $^{a}$ \\ Hiroshi Kado $^{a}$ Ryo Ishida ${ }^{a}$ Mayumi Nakata ${ }^{a}$ \\ Takashi Kitani $^{a} \quad K^{2}$ eiichi Tamagaki ${ }^{a}$ Chieko Sekita $^{b}$ \\ Atsuo Taniguchi ${ }^{\mathrm{b}}$ \\ ${ }^{a}$ Division of Nephrology, Kyoto Prefectural University of Medicine, Kyoto, and \\ bInstitute of Rheumatology, Tokyo Women's Medical University, Tokyo, Japan
}

\section{Key Words}

Chronic kidney disease - Familial juvenile hyperuricemic nephropathy - Gene mutation - Uromodulin

\begin{abstract}
We report the case of a Japanese family suffering from familial juvenile hyperuricemic nephropathy (FJHN) due to a rare missense mutation of the uromodulin (UMOD) gene. An 18-year-old male presented with gout, hyperuricemia, and stage 3 chronic kidney disease. Mostly, FJHN is caused by a mutation altering the cystine residue of UMOD/Tamm-Horsfall protein. However, in the present case, a T688C mutation was identified in exon 4, resulting in amino acid substitution with arginine replacing tryptophan at position 230 (Trp230Arg). This mutation was also found in his brother and father with the same phenotype, indicating autosomal dominant inheritance. The affected amino acid was conserved in 200 healthy Japanese controls. Therefore, mutation T688C most likely causes rare structural and/or functional abnormalities in UMOD/Tamm-Horsfall protein.
\end{abstract}




\section{Introduction}

Uromodulin (UMOD), also known as Tamm-Horsfall glycoprotein, is the most abundant protein excreted in the urine of healthy individuals. It is exclusively synthesized in the thick ascending limbs of Henle and the early distal convoluted tubule as a 640-amino-acid precursor protein. The primary structure of this protein includes a 24 amino-acid signal peptide at the $\mathrm{N}$ terminus followed by four calcium-binding epidermal growth factor-like domains, and one stretch of hydrophobic amino acids at the $\mathrm{C}$ terminus [1]. Mutations in chromosome 16p12 of the UMOD gene are known to cause autosomal dominant kidney diseases such as familial juvenile hyperuricemic nephropathy (FJHN), medullary cystic kidney disease type 2, and glomerulocystic disease [2]. We report the case of a Japanese family with clinical characteristics of FJHN caused by a rare missense mutation of the UMOD gene.

\section{Case Report}

An 18-year-old man with gouty arthritis in the right 1st metatarsal joint accompanied by hyperuricemia and renal impairment without any metabolic derangements, such as hypertension, diabetes, obesity, or alcohol abuse, was referred to our hospital by his family doctor for further examination. Although he had no medical history, family history revealed that his father had been diagnosed with hyperuricemia and renal impairment between 30 and 40 years of age and had been undergoing hemodialysis since the age of 50 . Moreover, his elder brother had also been diagnosed with hyperuricemia and renal impairment at age 21 .

The vital signs of the patient were stable at baseline: blood pressure was $116 / 60 \mathrm{~mm} \mathrm{Hg}$ and body mass index was 19.1. Physical examination revealed mild pain and swelling in the right 1st metatarsal joint, while other findings were normal. Hematuria and proteinuria were absent. Blood chemistry results revealed blood urea nitrogen, $13.1 \mathrm{mg} / \mathrm{dl}$; serum creatinine, $1.25 \mathrm{mg} / \mathrm{dl}$; uric acid, $9.8 \mathrm{mg} / \mathrm{dl}$; total cholesterol, $124 \mathrm{mg} / \mathrm{dl}$; triglyceride, $143 \mathrm{mg} / \mathrm{dl}$; and C-reactive protein, $0.01 \mathrm{mg} / \mathrm{dl}$. Chest X-ray and electrocardiography were normal. Renal ultrasonography showed normal appearance, which denies the possibility of medullary cystic kidney disease type 2 and glomerulocystic disease (fig. 1 ).

We also measured urinary uric acid excretion (EuA) and clearance $\left(\mathrm{C}_{\mathrm{UA}}\right)$ to determine the factors leading to hyperuricemia. EUA was at the lower limit $(0.48 \mathrm{mg} / \mathrm{kg} / \mathrm{h}$, laboratory range: $0.48-0.51$ $\mathrm{mg} / \mathrm{kg} / \mathrm{h}$ ), while $\mathrm{C}_{\text {UA }}$ was decreased $\left(4.9 \mathrm{ml} / \mathrm{min} / 1.73 \mathrm{~m}^{2}\right.$, laboratory range: $7.2-14.7 \mathrm{ml} / \mathrm{min} / 1.73$ $\mathrm{m}^{2}$ ). These results indicated that hyperuricemia in this patient was caused by decreased excretion of uric acid in the urine. We also examined his elder brother whose laboratory test values also indicated decreased uric acid excretion in the urine: serum creatinine, $1.25 \mathrm{mg} / \mathrm{dl}$; serum uric acid, $10.7 \mathrm{mg} / \mathrm{dl}$; EuA, $0.39 \mathrm{mg} / \mathrm{kg} / \mathrm{h} ; \mathrm{C}_{\mathrm{UA}}, 3.3 \mathrm{ml} / \mathrm{min} / 1.73 \mathrm{~m}^{2}$. Renal ultrasonography in the elder brother revealed relatively atrophic kidneys (longitudinal image; 8.2 and $8.8 \mathrm{~cm}$ in major axis of right and left kidney; fig. 1) without cystic lesions. Their father's kidney was hardly visible in ultrasound due to atrophy with some acquired cysts in end-stage renal disease (fig. 1). These findings, in addition to the father's medical history, suggested that the family suffers from FJHN. The patient and his elder brother were treated with allopurinol. They had normal serum uric acid levels when measured at their recent visit to our hospital and remained clinically asymptomatic throughout this period.

Following an approval from our Institutional Review Board (IRB)/Ethics Committe, we obtaine d a written informed consent from the patient, his elder brother, and their father to collect peripheral blood samples for gene analysis. Exons 2-12 were analyzed for DNA sequence, including the splice site of the UMOD gene, for genetic confirmation of FJHN. As shown in fig. 2 , the analysis revealed a rare heterozygous missense mutation (c.688 T >C, pTrp 230Arg) in exon 4 that altered evolutionary conserved residues in the gene encoding UMOD [3]. In contrast, this mutation was not found in 200 healthy Japanese controls (personal communication). 


\section{Discussion}

FJHN is a rare autosomal dominant disease caused by mutations in the UMOD gene and characterized by hyperuricemia, gout, tubulointerstitial nephropathy, and endstage renal disease. Approximately 40 mutations in the UMOD gene have been described [4-8]. In contrast to the rare mutation found in the present case ( $\mathrm{p}$ Trp $230 \mathrm{Arg}$ ), the majority of reported mutations involve an exchange resulting in the deletion or addition of a cysteine residue [5]. In 2010, Zaucke et al. [9] reported the case of a 36-year-old patient with stage 3 chronic kidney disease and the same novel missense mutation as our family cases. In their report, the patient's sister and father had ESRD with gout. However, no DNA was available for analysis from either of them. Hence, a definite correlation between the $\mathrm{p}$ Trp 230Arg mutation and renal outcome of FJHN was unclear in their report. To our knowledge, this is the first report verifying that a familial lineage of $\mathrm{p}$ Trp 230Arg mutation is clearly associated with FJHN. Analysis using PolyPhen software (http://genetics.bwh.harvarad.edu/pph/index.html) revealed that the substitution of $\mathrm{p}$ Trp 230Arg would probably have a damaging effect with a significant position-specific independent count score difference of 3.902 [9]. Indeed, in our report, the family history combined with gene analysis indicates an unfavorable renal outcome of FJHN with a c.688 $\mathrm{T}>\mathrm{C}$ mutation.

The biologic function of UMOD is not completely understood and the mechanism by which UMOD mutations cause renal failure also remains unclear. The pathologic findings in FJHN with UMOD mutations are reported to be interstitial fibrosis, tubular atrophy, and tubular basement membrane thickening and splitting [8]. The majority of UMOD mutations that have been identified are missense mutations in exon 4, which encodes for calcium-binding epidermal growth factor-like domains of UMOD. UMOD mutations mainly alter cysteine amino acids, in contrast to the situation in our case. UMOD mutations for cysteine often cause disruption of the molecule's stable tertiary structure, resulting in altered protein-folding accumulation within endoplasmic reticulum (ER), and impaired trafficking. Electron microscopy in thick ascending limbs of Henle tubules demonstrated massive intracellular UMOD inclusions detected by immunocytochemistry and abundant fibrillar or granular storage material within the bundle of ERs [8]. In contrast, renal histology in a patient with a p Trp 230Arg mutation revealed a significant decrease in UMOD-positive tubules, especially in the primary cilia [9]. Indeed, not all families with a UMOD mutation have UMOD inclusions in tubules [3]. The diversity of UMOD function may affect different phenotypes in each mutation. It is speculated that the primary cilia in the tubules sense urinary flow and vectorial information for orientated cell division using many mediators, such as nephrocystin-1 and/or kinestin family member 3A [9]. Thus, UMOD is part of a multiprotein complex and takes part in the maintenance of cilia. Further studies are required to address the specific role of cilia UMOD in the pathogenesis of FJHN.

In conclusion, physicians should be suspicious of FJHN in young adult patients who present hyperuricemia with a family history and ask the suitable institute to perform DNA analysis of UMOD. Although FJHN associated with the p Trp 230Arg mutation is very rare, further analysis of this particular alteration in the UMOD protein and accumulation of clinical information from case reports would be useful for developing a therapeutic approach for FJHN. 


\section{Disclosure Statement}

The authors declare that they have no conflicts of interest.
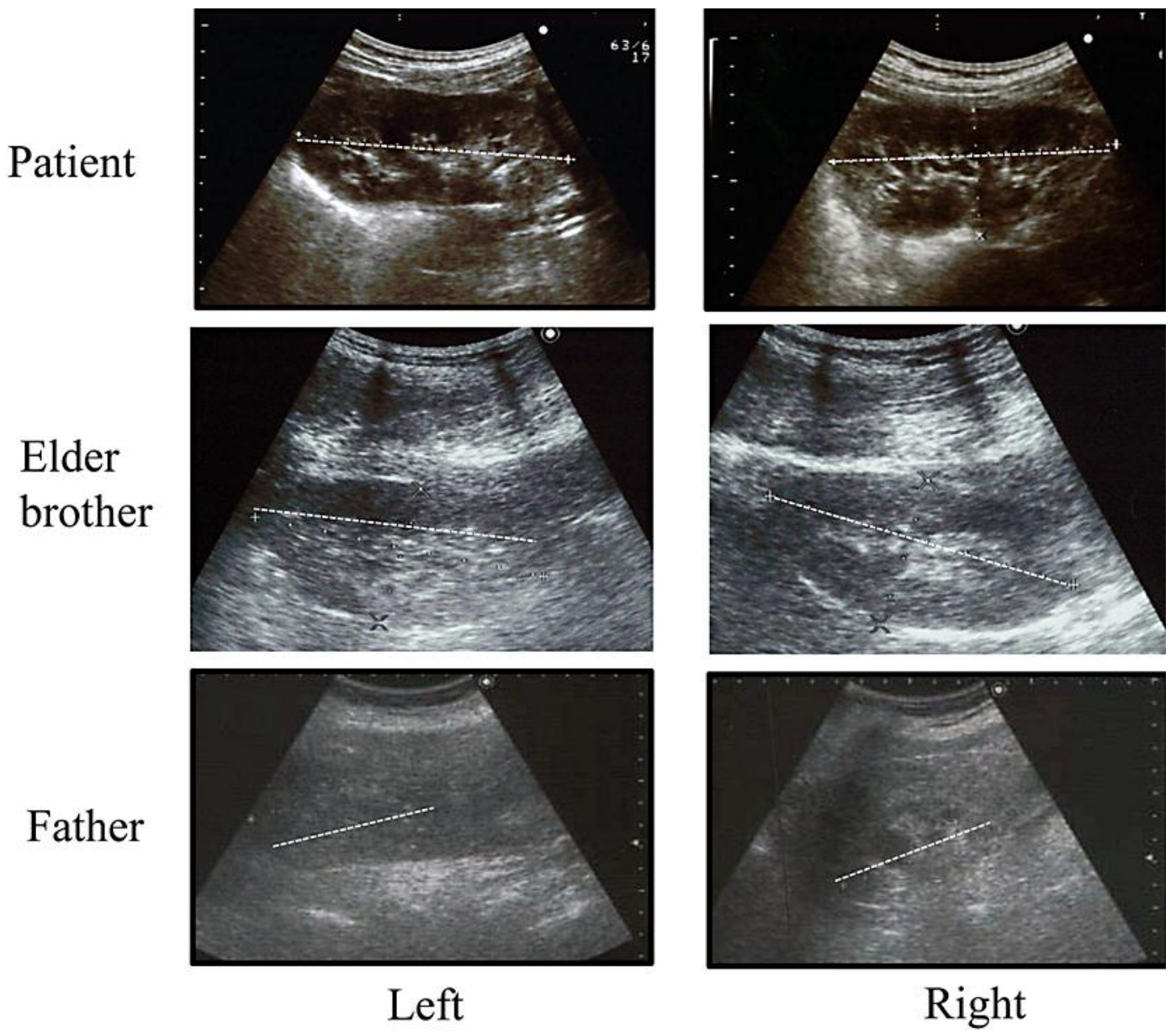

Fig. 1. Findings of renal ultrasound from the patient, his elder brother and their father. 


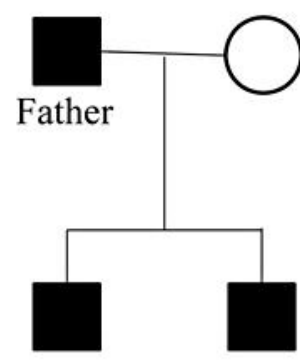

Elder brother

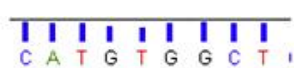

Normal

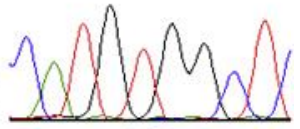

$\mathrm{C} / \mathrm{T}$

Father

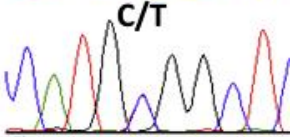

Elder

brother

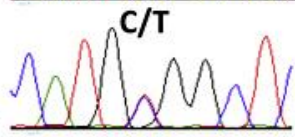

Patient

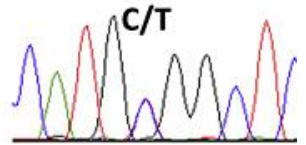

Fig. 2. A mutation analysis was carried out on a healthy volunteer. UMOD gene mutation analysis in the patient with FJHN showed a heterozygous mutation in exon 4 of the UMOD gene (c.688 T>C), which led to the p.Trp 230Arg mutation. Reverse sequencing further confirmed the mutation. The patient's elder brother possessed the same mutation, as did their father.

\section{References}

1 Serafini-Cessi F, Malagolini N, Cavallone D: Tamm-Horsfall glycoprotein: biology and clinical relevance. Am J Kidney Dis 2003;42:658-676.

-2 Dahan K, Devuyst O, Smaers M, Vertommen D, Loute G, Poux JM, Viron B, Jacquot C, Gagnadoux MF, Chauveau D, Büchler M, Cochat P, Cosyns JP, Mougenot B, Rider MH, Antignac C, Verellen-Dumoulin C, Pirson Y: A cluster of mutation in the UMOD gene causes familial juvenile hyperuricemic nephropathy with abnormal expression of uromodulin. J Am Soc Nephrol 2003;14:2883-2893.

-3 Hart TC, Gorry MC, Hart PS, Woodard AS, Shihabi Z, Sandhu J, Shirts B, Xu L, Zhu H, Barmada MM, Bleyer AJ: Mutations of the UMOD gene are responsible for medullary cystic kidney disease 2 and familial juvenile hyperuricaemic nephropathy. J Med Genet 2002;39:882-892.

4 Kudo E, Kamatani N, Tezuka O, Taniguchi A, Yamanaka H, Yabe S, Osabe D, Shinohara S, Nomura K, Segawa M, Miyamoto T, Moritani M, Kunika K, Itakura M: Familial juvenile hyperuricemic nephropathy: detection of mutations in the uromodulin gene in five Japanese families. Kidney Int 2004;65:1589-1597.

$\checkmark 5$ Calado J, Gaspar A, Clemente C, Rueff J: A novel heterozygous missense mutation in the UMOD gene responsible for familial juvenile hyperuricemic nephropathy. BMC Med Genet 2005;6:5.

-6 Bernascone I, Vavassori S, Di Pentima A, Santambrogio S, Lamorte G, Amoroso A, Scolari F, Ghiggeri GM, Casari G, Polishchuk R, Rampoldi L: Defective intracellular trafficking of uromodulin mutant isoforms. Traffic 2006;7:1567-1579.

7 Vylet’al P, Kublová M, Kalbácová M, Hodanová K, Baresová V, Stibůrková B, Sikora J, Hůlková H, Zivný J, Majewski J, Simmonds A, Fryns JP, Venkat-Raman G, Elleder M, Kmoch S: Alterations of uromodulin biology: a common denominator of the genetically heterogeneous FJHN/MCKD syndrome. Kidney Int 2006;70:1155-1169.

-8 Nasr SH, Lucia JP, Galgano SJ, Markowitz GS, D’Agati VD: Uromodulin storage disease. Kidney Int 2008;73:971-976.

>9 Zaucke F, Boehnlein JM, Steffens S, Polishchuk RS, Rampoldi L, Fischer A, Pasch A, Boehm CW, Baasner A, Attanasio M, Hoppe B, Hopfer H, Beck BB, Sayer JA, Hildebrandt F, Wolf MT: Uromodulin is expressed in renal primary cilia and UMOD mutations result in decreased ciliary uromodulin expression. Hum Mol Genet 2010;19:1985-1999. 